\title{
Experimental Analysis of Solar Operated Thermo-Electric Heating and Cooling System
}

\author{
Mr. Swapnil B. Patond ${ }^{\# 1}$, Miss. Priti G. Bhadake ${ }^{\# 2}$, Mr. Chetan B. Patond ${ }^{\# 3}$ \\ \#1,2 Scholar M.E. (2 $2^{\text {nd }}$ year/ Thermal Engg.), \\ \#3 Scholar B.E. (4 ${ }^{\text {th }}$ year/ Mech.), \\ \#1, 2 P. R. Pote Engg. Colg. Amravati, (M.S.), India \\ \#3 G. H. Raisoni Engg. Colg. Amravati, (M.S.), India
}

\begin{abstract}
The main objective of our project is to design \& make analysis of a Heating \& Cooling system which utilizes non-conventional energy source (i.e. Solar Energy) with the help of Thermoelectric Module which works on the principle of the Peltier effect. This will be a suitable $\&$ affordable system for the people living in remote part of India where loadshading is a major problem. The major difference between the existing system $\&$ our system is that, our project works without use of mechanical device \& without refrigerant too. As the module is compact in size one can design (i.e. shape, capacity) the system according to his requirement.

In this paper an attempt has been made to conduct an experimental study on small scale solar operated thermoelectric Heating \& Cooling system.
\end{abstract}

Key Words: Thermo-Electric Module, Peltier Effect, Solar Energy,

\section{INTRODUCTION}

Renewable \& alternative non-conventional green energy technologies used for heat-pumping applications have shown real merits and received renewed interest in recent years especially in smallscale portable heating applications. Solar-driven thermoelectric heat pumping is one of these innovative technologies [1]. Solar energy is the most low cost, competition free, universal source of energy as sunshine's throughout. This energy can be converted into useful electrical energy using photovoltaic technology.

Thermoelectric heating (or cooling) technology has received renewed interest recently due to its distinct features compared to conventional technologies, such as vapourcompression and electric heating (or cooling) systems. Thermoelectric (TE) modules are solidstate heat pumps (or refrigerators in case of cooling) that utilize the Peltier effect between the junctions of two semiconductors. The TE modules require a DC power supply so that the current flows through the TE module in order to cause heat to be transferred from one side of the TE module to other, thus creating a hot and cold side [2,3].

The main objective of the heating \& cooling system service is to be suitable for use by the people who live in the remote areas of country where load-shading is a major problem. The system can also be used for remote parts of the world or outer conditions where electric power supply is not readily available.

\section{LITERATURE REVIEW}

As we know that, the physical principles upon which modern thermoelectric coolers are based actually date back to the early 1800 's, although commercial thermoelectric (TE) modules were not available until almost 1960. The first important discovery relating to thermoelectricity occurred in 1821 when a German scientist, Thomas Seebeck, found that an electric current would flow continuously in a closed circuit made up of two dissimilar metals provided that the junctions of the metals were maintained at two different temperatures [4]. In 1834, a French watchmaker and part time physicist, Jean Peltier, while investigating the "Seebeck Effect," discovered the "Peltier Effect" and it is the fundamental principal behind a thermo-electric system [5].

There are a number of experimental and numerical studies that characterized the performance of TE heating and cooling systems. For example, Luo, et al.[6] performed experiments and verified that a TEHP system is more efficient than an electrical heating device, for its heating coefficient reached more than 1.6 with suitable operating conditions. Riffat and Qiu [7] compared the performance of the thermoelectric airconditioner with two other types of domestic airconditioners, namely the vapour compression airconditioner and the absorption air-conditioner.

Bansal and Martin [8] investigated and compared the performance characteristics of three domestic refrigerators, namely the vapourcompression, the thermoelectric and the absorption refrigerators based on actual experimental data. Bansal and Martin [8] also reported that as the TE technology has advanced, the reliability and cost of TE cooling systems have changed favorably and at present TE systems are available for the domestic market at comparable prices. Min and Rowe [9] investigated a number of prototype TE-coolers and evaluated their performances in terms of the COP. Dai et al.[10] conducted an experimental investigation on a portable solar-TE refrigerator for small-scale remote applications or in areas where electric supply is unavailable. Their results showed 
that the unit can maintain the inside temperature at $5-10^{\circ} \mathrm{C}$, and have a COP of approximately 0.3 .

\section{CONSTRUCTION}

Here this system heat or cool the product using thermo-electricmodule.the construction set up for this system require following parts

1. Solar panel, 2. Insulated Box (2 chambers),

3. Charge controller, 4. Battery

5. Fins, thermister, 6.Exaust fan,circuit kit,

7. Thermoelectric module.

8. Metal (aluminium box,sheets)

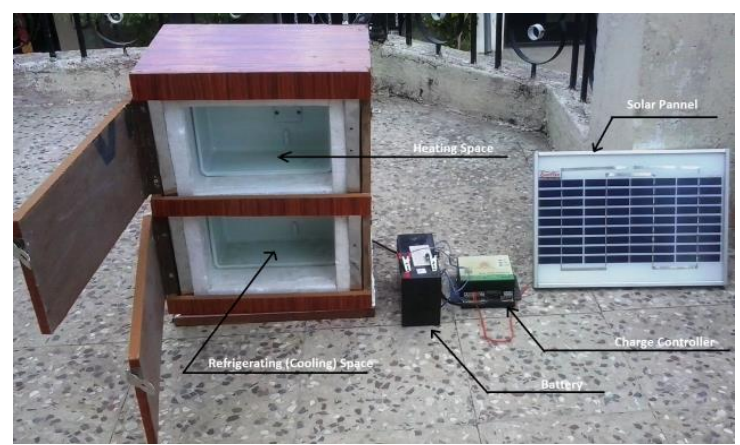

Figure 1: Designed Thermoelectric Heating \& Cooling system.

\section{A. Thermoelectric Module}

A typical thermoelectric module is composed of two ceramic substrates that serve as a foundation and electrical insulation for P-type and N-type Bismuth Telluride dice that are connected electrically in series and thermally in parallel between the ceramics. The ceramics also serve as insulation between the modules internal electrical elements and a heat sink that must be in contact with the hot side as well as an object against the cold side surface. Electrically conductive materials, usually copper pads attached to the ceramics, maintain the electrical connections inside the module. Solder is most commonly used at the connection joints to enhance the electrical connections and hold the module together [11]. Most modules have and even number of P-type and $\mathrm{N}$-type dice and one of each sharing an electrical interconnection is known as, "a couple." [11].

While both P-type and N-type materials are alloys of Bismuth and Tellurium, both have different free electron densities at the same temperature. P-type dice are composed of material having a deficiency of electrons while $\mathrm{N}$-type has an excess of electrons. As current flows up and down through the module it attempts to establish a new equilibrium within the materials. The current treats the P-type material as a hot junction needing to be cooled and the N-type as a cold junction needing to be heated. Since the material is actually at the same temperature, the result is that the hot side becomes hotter while the cold side becomes colder. The direction of the current will determine if a particular die will cool down or heat up. In short, reversing the polarity will switch the hot and cold sides [12].

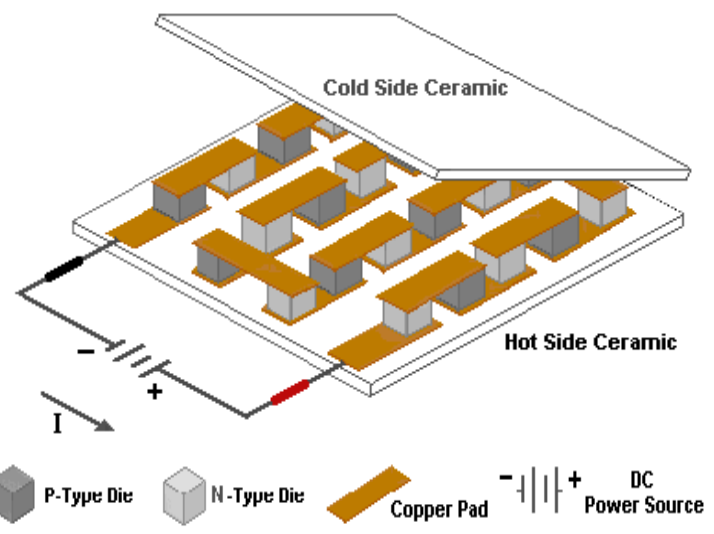

Figure 2: Internal construction of thermo- electric module (adapted from ADVANCED THERMOELECTRIC · One Tara Boulevard · Nashua, NH 03062 - USA) [11].

\section{OPERATING PRINCIPLE OF THE THERMO-ELECTRIC MODULE}

The TEM operating principle is based on the Peltier effect. The Peltier effect is a temperature difference created by applying a voltage between two electrodes connected to a sample of semiconductor material to create a hot side and a cold side. The cold side of the thermoelectric module is utilized for refrigeration purposes; provide cooling to the refrigerator space. On the other hand, the heat from the hot side is utilized for heating purpose.

In a thermo-electric heat exchanger the electrons acts as the heat carrier. The heat pumping action is therefore function of the quantity of electrons crossing over the p-n junction [8].

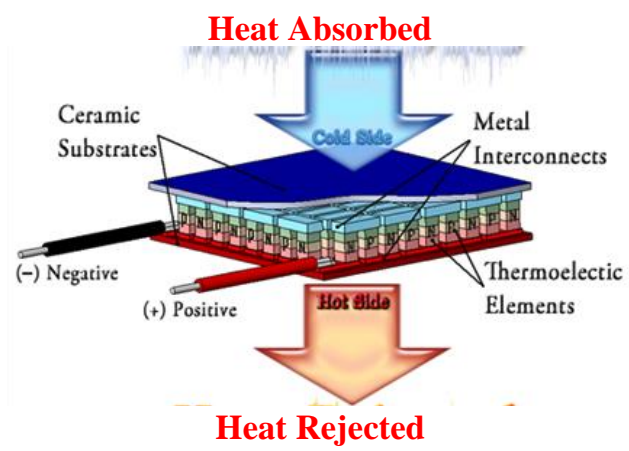

Figure 3: Operating principle of thermo-electric module (adapted from scientific and production firm module-ISO 9001)

\section{WORKING OF THERMOELECTRIC MODULE}

Thermoelectric modules are solid-state heat pumps that operate on the Peltier effect (see definitions). A thermoelectric module consists of an array of p- and n-type semiconductor elements that are heavily doped with electrical carriers. The elements are arranged into array that is electrically connected in series but thermally connected in parallel. This array is then affixed to two ceramic substrates, one on each side of the elements (see 
figure below). Let's examine how the heat transfer occurs as electrons flow through one pair of p- and n-type elements (often referred to as a "couple") within the thermoelectric module:

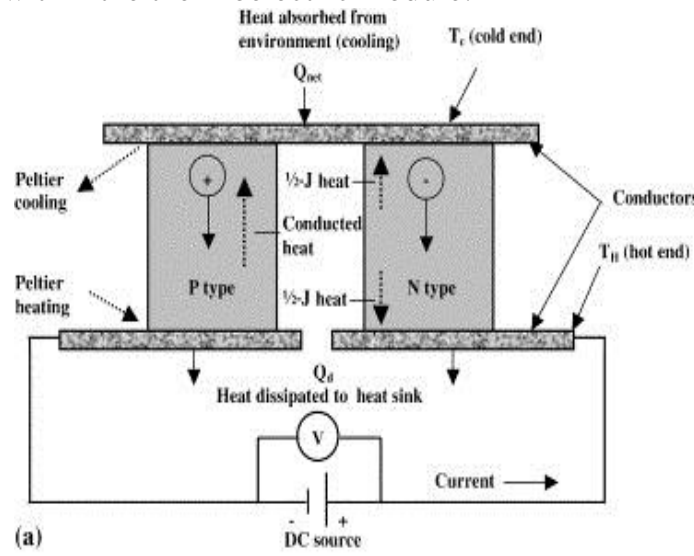

Figure4: Schematic diagram of thermoelectric cooling [16]

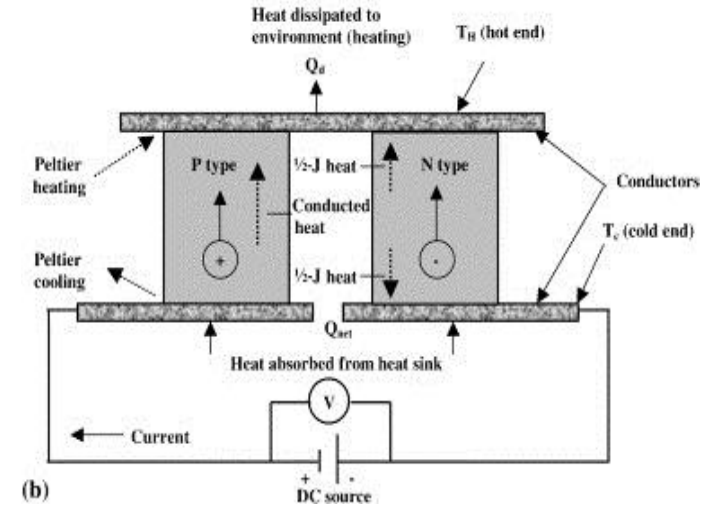

Figure 5: Schematic diagram of thermoelectric heating [16]

The p-type semiconductor is doped with certain atoms that have fewer electrons than necessary to complete the atomic bonds within the crystal lattice. When a voltage is applied, there is a tendency for conduction electrons to complete the atomic bonds. When conduction electrons do this, they leave "holes" which essentially are atoms within the crystal lattice that now have local positive charges. Electrons are then continually dropping in and being bumped out of the holes and moving on to the next available hole [8]. In effect, it is the holes that are acting as the electrical carriers.

Now, electrons move much more easily in the copper conductors but not so easily in the semiconductors. When electrons leave the p-type and enter into the copper on the cold-side, holes are created in the p-type as the electrons jump out to a higher energy level to match the energy level of the electrons already moving in the copper. The extra energy to create these holes comes by absorbing heat. Meanwhile, the newly created holes travel downwards to the copper on the hot side. Electrons from the hot-side copper move into the p-type and drop into the holes, releasing the excess energy in the form of heat. The n-type semiconductor is doped with atoms that provide more electrons than necessary to complete the atomic bonds within the crystal lattice. When a voltage is applied, these extra electrons are easily moved into the conduction band. However, additional energy is required to get the n-type electrons to match the energy level of the incoming electrons from the cold-side copper. The extra energy comes by absorbing heat. Finally, when the electrons leave the hot-side of the n-type, they once again can move freely in the copper. They drop down to a lower energy level, and release heat in the process.

\section{A. Technical Specification}

Thermoelectric modules withstand potentially detrimental environmental conditions operating without failure under the low temperature point being equal to $285 \mathrm{~K}\left(12^{\circ} \mathrm{C}\right)$ and the high temperature point being equal to $328 \mathrm{~K}\left(+55^{\circ} \mathrm{C}\right)$. Thermoelectric modules successfully meet the below specified conditions without failure: sinusoidal vibration, 10-50 Hertz, with vibroacceleration amplitude up to $20 \mathrm{~m} / \mathrm{s}^{2}(2 \mathrm{~g})$. Unsealed thermoelectric modules withstand high humidity conditions with the RH level up to $88 \%$ and $298^{\circ}$ $\mathrm{K} \quad\left(25^{\circ} \mathrm{C}\right)$ without any failure in operation. Thermoelectric modules withstand single mechanical shock with the peak shock acceleration being equal to $20 \mathrm{G}\left(200 \mathrm{~m} / \mathrm{s}^{2}\right)$ and $2-4 \mathrm{msec}-$ Collision Momentum without any failure [13].

\section{B. Insulation Resistance Requirements}

Insulation resistance of thermoelectric modules between the electrodes and outer surfaces of the ceramic plates is no less $20 \mathrm{M} \mathrm{Ohms}$ at the test DC voltage of 100 Volts under such standard climatic conditions as $25 \pm 10^{\circ} \mathrm{C}, 45-80 \% \mathrm{RH}$ and 84-106, $7 \mathrm{KPa}$ atmospheric pressure [13].

\section{Reliability}

Reliability is one of the major criterions of thermoelectric module (TEM) selection. TEMs are considered to be highly reliable components due to their solid-state construction. However premature TEM failure roots in soldered joints degradation which is primarily caused by the following factors: Improper operation and faulty mounting of TEM's leads to catastrophic electrical or mechanical failure; Continuous exposure to an elevated temperature results in TEM's is overheating. It is important that the modules are installed in full accordance with these general instructions to minimize the possibility of premature TEM failure. If you choose the right TEM or calculate/ design a thermoelectric cooling assembly, please take into account TEM's operating temperature, which is 
TEM's hot side temperature [14]. This is highly important since if the TEM is exposed to the higher temperature range, this will result in degradation changes in semiconductor material parameters and subsequent TEM's failure. We have used TEMs with the operating temperature of $80^{\circ} \mathrm{C}$ or $150^{\circ} \mathrm{C}$. According to the tests' results, the Mean Time between Failures (MTBFs) for TEMs is in excess of 200,000 hours at ambient room temperature. It is recommended, however, to design thermoelectric cooling assemblies in such a way as to provide the maximum heat dissipation from the TEM hot side to minimize the possibility of premature TEM failure [15].

\section{EXPERIMENTAL ANALYSIS}

\section{A. Cooling of water by Convection}

We were doing experiments and note down readings Temperature vs Time and drawn this graph. In this graph we use insulator (thermocol) between metal bowl and surface of cooling chamber. Graph shows temp decreases from $30^{\circ} \mathrm{C}$ to $20{ }^{\circ} \mathrm{C}$ within 90 minutes. The cooling rate of water by convection in cooling chamber (3020) $/ 90=0.111$.

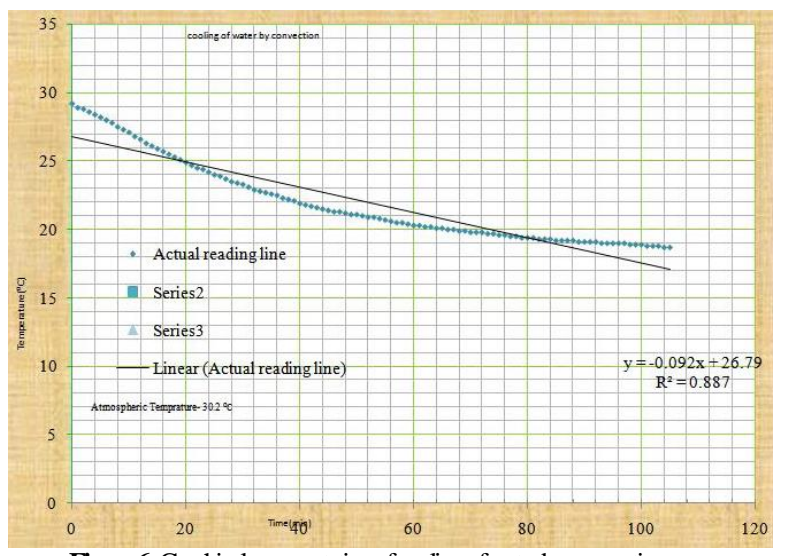

Figure 6: Graphical representation of cooling of water by convection.

\section{B. Cooling of water by Conduction:}

In above graph we cooling water by conduction means there was direct contact between metal bowls in which we taken water and surfaces of the cooling chamber. Graph show the cooling rate is higher at the starting up to $22^{\circ}$. Within 90 minutes' temp decreases from $30{ }^{\circ} \mathrm{C}$ to $17{ }^{\circ} \mathrm{C}$. The cooling rate of water by conduction is $(30-17) / 90=0.144$ .The cooling rate of water by conduction is higher than the cooling rate of water by convection.

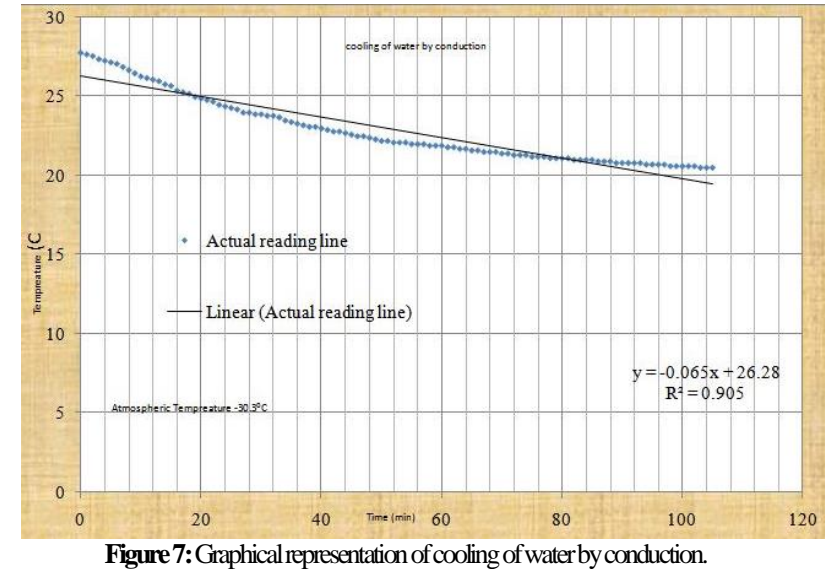

C. Cooling of Fruit (Orange):

We also analyze on fruits like Orange. Here orange fruit is cooled in cooling chamber. Then note down readings Temperature Vs Time graph shows initially fruit cooled fastly. Temp decreases from $28^{\circ} \mathrm{C}$ to $22^{\circ} \mathrm{C}$. within 20 minutes and then took 80 minutes to decrease another $4 \circ \mathrm{C}$. The cooling rate for Orange is $(28-22) / 20=0.3$.

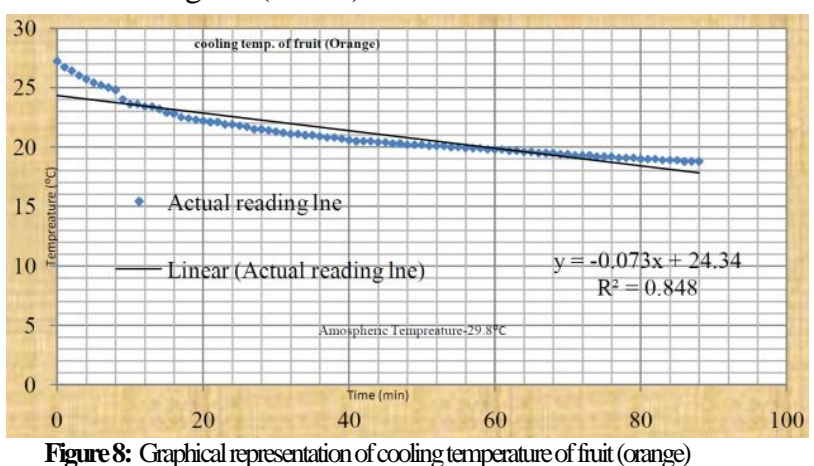

D. Cooling of Metal (Aluminum):

Above graph refers to cooling of aluminum. The graph shows that aluminum is cooled from $28^{\circ} \mathrm{C}$ to $19^{\circ} \mathrm{C}$ within 50 minutes, the cooling rate is $(28-19) / 50=0.18$. That is cooling rate is higher than others metal like (copper and silver).

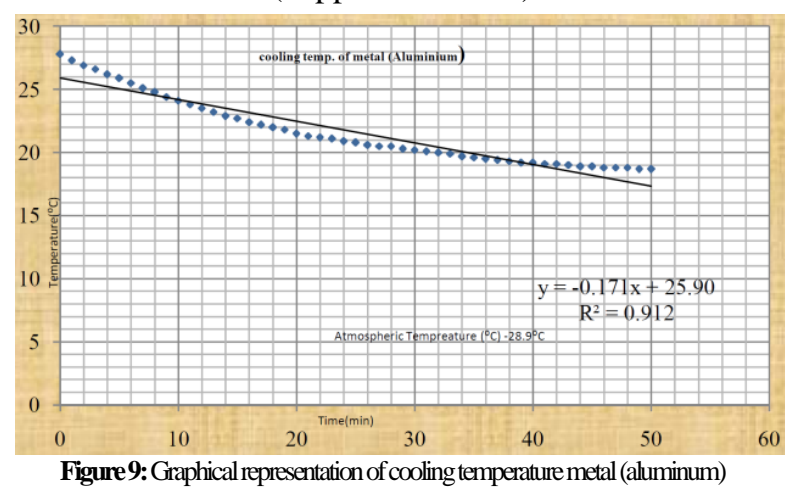

E. Heating of Water by Conduction:

In this graph we analyze heating effect. We use direct contact of metal bowl in the heating chamber for heating of water by conduction.Graph indicates 
temp increases linearly with time. Water gains $17^{\circ} \mathrm{C}$ to $50.3^{\circ} \mathrm{C}$ within 49 minutes. The heating rate is $(50.3-17) / 49=0.679$. We found that the heating rate is higher than cooling rate.

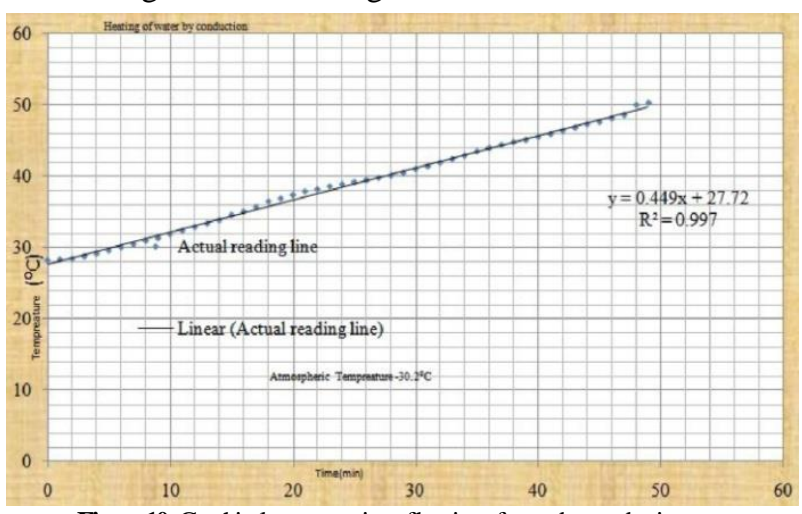

Figure 10: Graphical representation of heating of water by conduction.

\section{ADVANTAGES}

We believe that thermoelectric cooling offers a number of advantages over traditional refrigeration methods, as:

1. System have no moving parts,

2. No Freon's or other liquid or gaseous refrigerants required,

3. Precise temperature control,

4. High reliability \& durability - We guarantee 5 years hours of no failures,

5. Compact size and light weighted,

6. Noiseless operation,

7. Relatively low cost and high effectiveness,

8. Easy for maintenance,

9. Eco-friendly C-pentane, $\mathrm{CFC}$ free insulation.

\section{DISADVANTAGE}

1. C.O.P. is less as compared to conventional refrigeration system.

2. Suitable only for low cooling capacity.

\section{LIMITATION}

In rainy season it cannot be possible to charge battery due to irregular atmospheric condition as our project is totally based on solar energy. This is the limitation of our project, but this problem can be solved by giving direct electric supply.

\section{APPLICATIONS OF SYSTEMS}

1. Can be uses for remote place where electric supply is not available,

2. Medical and pharmaceutical equipment,

3. Military applications,

4. Laboratory, scientific instruments, computers and video cameras.

5. In restaurants /hotels

\section{FUTURE SCOPE}

To build a real time model replacing both air conditioner \& room heater in one system i.e. thermoelectric hot \& cold room conditioner.

\section{CONCLUSION}

A portable Heating \& Cooling system was fabricated using thermoelectric module \& electric control unit \& tested for the cooling and heating purpose. The system is self powers \& can be used in isolated \& a remote part of the country where load-shading is a major problem. The important aspect to be noted is that it is a onetime investment $\&$ is free from maintenance.

The heating \& cooling rates for different modes of heat transfer (conduction \& convection) for water; fruit (orange) \& metal (Al) are analyzed. Analysis of various materials such as metal, fruit and water is plotted on graph as time on $\mathrm{X}$-axis and temperature on Y-axis. The analysis of various materials indicates that

a. Cooling rate for conduction of water is higher compared with convection of water.

b. The heating rate of water is higher than cooling rate.

Further improvement in the efficiency of the system may be possible through improving module contact-resistance \& thermal interfaces. This could be achieved by installing more modules in order to cover a greater surface area of the system.

\section{REFERENCES}

[1] Angrist, S.W., 1971. Direct Energy Conversion (Allyn and Bacon, Inc., Boston, MA,).

[2] Ismail, B. I., Ahmed,W. (2009). Thermoelectric Power Generation using Waste-Heat Energy as an Alternative Green Technology. Recent Patents on Electrical Engineering, 2(1), $27-$ 39.

[3] Riffat, S. B., Ma, X. (2004). Improving the Coefficient of Performance of Thermoelectric Cooling Systems: a Review. International Journal of Energy Research, 28, 753-768.

[4] Omega.(n.d.)The thermocouple. Retrieved October 10, 2010, from http://www.omega.com /temperature/ z / pdf/z021-032.pdf [5] Riffat SB. Xiaolima Thermo-Electric: A Review of Present and Potential Applications. Applied Thermal Engg. International Journal of Engineering(IJE),Volume(5): Issue(1):2011, 2003:23:913- 35.

[6] Luo, Q., Tang, G., Liu, Z., Wang, J. (2005). A Novel Water Heater Integrating Thermoelectric Heat Pump with Separating Thermo siphon. Applied Thermal Engineering, 25, 2193-2203.

[7] Riffat, S. B., Qiu, G. (2004). Comparative Investigation of Thermoelectric Air-Conditioners versus Vapour Compression and Absorption Air-Conditioners. Applied Thermal Engineering, 24, 1979-1993.

[8] Bansal, P. K., Martin, A. (2000). Comparative Study ofVapour Compression, Thermoelectric andAbsorption Refrigerators. International Journal of Energy Research, 24, 93107. 
[9] Min, G., Rowe, D. M. (2006). Experimental Evaluation of Prototype Thermoelectric Domestic-Refrigerators. Applied Energy, 83, 133-152.

[10] Dai, Y. J., Wang, R. Z., Ni, L. (2003). Experimental Investigation on a Thermoelectric Refrigerator Driven by Solar Cells. Renewable Energy, 28, 949-959.

[11] Advance Thermoelectric. One Tara Boulevard.Nashu,NH03062.Us.

[12] Abdul - Wahab, S.A., A. Elkamel, A.M. Al - Damkhi, I.A. Al - Habsi, H. Al - Rubai'ey, A. Al - Battashi, A. Al -Tamimi, K. Al-Mamari and M. Chutani, 2009. Omani Bedouins' readiness to accept solar thermoelectric refrigeration systems. International J. Energy Technology and Policy, 7: 127-136.
[13] D. Vashaee, And A. Shakouri, "Electronic and Thermoelectric Transport in Semiconductor and Metallic Super lattices," Journal of Applied Physics, Vol. 95, No.3, pp. 12331245, February 2004.

[14] Solar Concentrator for Combined Heat and Thermoelectric Power Generation. Energy Conversion \& Management 2000; 41: 737-756

[15] P. Ancey, M. Gshwind, New Concept of Integrated Peltier Cooling Device for the Preventive Detection of Water Condensation", Sensors and Actuators B 26-27 (1995) Pp. 303307.

[16] En.Wikipedia.Org/Thermo Electric Effect. 